@ERSpublications

Small airway obstruction markers are stable over time and have potential as outcome measures in clinical trials http://ow.ly/tCzp2

Sherif Gonem ${ }^{1}$, Steven Corkill ${ }^{1}$, Amisha Singapuri ${ }^{1}$, Per Gustafsson ${ }^{2}$, Rino Costanza ${ }^{3}$, Christopher E. Brightling ${ }^{1}$ and Salman Siddiqui ${ }^{1}$

${ }^{1}$ Institute for Lung Health, Dept of Infection, Immunity and Inflammation, University of Leicester, Leicester, and ${ }^{3}$ Chiesi Ltd, Cheadle, UK. ${ }^{2}$ Dept of Paediatrics, Central Hospital, Skövde, Sweden.

Correspondence: Sherif Gonem, Respiratory Research BRU, Glenfield Hospital, Groby Road, Leicester, LE3 9QP, UK. E-mail: sg330@le.ac.uk

Received: Jan 032014 | Accepted after revision: Feb 082014 | First published online: March 062014

Support statement: This article presents independent research funded by the National Institute for Health Research (NIHR). The views expressed are those of the authors and not necessarily those of the National Health Service, the NIHR or the Dept of Health. This work was partly funded through research collaborations with Chiesi Farmaceutici SPA. Additional funding was received from the Airway Disease Predicting Outcomes through Patient Specific Computational Modelling (AirPROM) project (funded through FP7 European Union grant 270194).

Conflict of interest: Disclosures can be found alongside the online version of this article at www.erj.ersjournals.com

\title{
References
}

1 van den Berge M, ten Hacken NH, van der Wiel E, et al. Treatment of the bronchial tree from beginning to end: targeting small airway inflammation in asthma. Allergy 2013; 68: 16-26.

2 Goldman MD, Saadeh C, Ross D. Clinical applications of forced oscillation to assess peripheral airway function. Respir Physiol Neurobiol 2005; 148: 179-194.

3 Robinson PD, Latzin P, Verbanck S, et al. Consensus statement for inert gas washout measurement using multipleand single- breath tests. Eur Respir J 2013; 41: 507-522.

4 Gonem S, Natarajan S, Desai D, et al. Clinical significance of small airway obstruction markers in patients with asthma. Clin Exp Allergy 2014; 44: 499-507.

5 Farah CS, King GG, Brown NJ, et al. The role of the small airways in the clinical expression of asthma in adults. J Allergy Clin Immunol 2012; 129: 381-387.

6 Global Initiative for Asthma. Global Strategy for Asthma Management and Prevention. www.ginasthma.org/local/ uploads/files/GINA_Report_March13.pdf Date last updated: 2012.

7 British Thoracic Society. Asthma Guideline. www.brit-thoracic.org.uk/guidelines-and-quality-standards/asthmaguideline/ Date last updated: January 2012.

8 Juniper EF, Svensson K, Mörk AC, et al. Measurement properties and interpretation of three shortened versions of the asthma control questionnaire. Respir Med 2005; 99: 553-558.

9 Oostveen E, MacLeod D, Lorino $\mathrm{H}$, et al. The forced oscillation technique in clinical practice: methodology, recommendations and future developments. Eur Respir J 2003; 22: 1026-1041.

10 Horsley AR, Gustafsson PM, Macleod KA, et al. Lung clearance index is a sensitive, repeatable and practical measure of airways disease in adults with cystic fibrosis. Thorax 2008; 63: 135-140.

11 Verbanck S, Schuermans D, van Muylem A, et al. Ventilation distribution during histamine provocation. J Appl Physiol 1997; 83: 1907-1916.

12 Horsley AR, Macleod KA, Robson AG, et al. Effects of cystic fibrosis lung disease on gas mixing indices derived from alveolar slope analysis. Respir Physiol Neurobiol 2008; 162: 197-203.

13 Kirkwood BR, Sterne JAC. Essential Medical Statistics, 2nd Edn. Oxford, Blackwell Publishing Ltd, 2003; pp. 420-421.

14 Yamaguchi M, Niimi A, Ueda T, et al. Effect of inhaled corticosteroids on small airways in asthma: investigation using impulse oscillometry. Pulm Pharmacol Ther 2009; 22: 326-332.

15 Heaney LG, Brightling CE, Menzies-Gow A, et al. Refractory asthma in the UK: cross-sectional findings from a UK multicentre registry. Thorax 2010; 65: 787-794.

\section{Bronchial obstruction and reversibility in children: inspiratory or expiratory resistance?}

To the Editor:

Assessing bronchial obstruction and reversibility is of help in diagnosing asthma. The forced oscillation technique (FOT) has gained popularity in children since minimal cooperation is required. Owing to the fact 
TABLE 1 Subject characteristics, baseline lung function and response to salbutamol

\begin{tabular}{|c|c|c|c|}
\hline & Control & Asthma & $p$-value ${ }^{\#}$ \\
\hline Subjects $n$ & 23 & 55 & \\
\hline Age years & $7.8 \pm 1.8$ & $8.1 \pm 1.5$ & NS \\
\hline Height $\mathrm{cm}$ & $130 \pm 14$ & $129 \pm 9$ & NS \\
\hline FEV1 z-score & $0.6 \pm 1.1$ & $0.3 \pm 1.0$ & NS \\
\hline Rrs,i hPa $\cdot \mathbf{S} \cdot \mathrm{L}^{-1}$ & $6.3 \pm 1.7$ & $8.8 \pm 3.1$ & $<0.001$ \\
\hline Rrs,e hPa $\cdot \mathrm{s} \cdot \mathrm{L}^{-1}$ & $6.8 \pm 2.0^{\circ}$ & $10.0 \pm 3.9$ & $<0.001$ \\
\hline Rrs,e-i hPa $\cdot s \cdot L^{-1}$ & $0.6 \pm 0.8$ & $1.2 \pm 1.5$ & 0.07 \\
\hline Subjects $\mathrm{n}$ & $\overline{20}$ & $\overline{53}$ & \\
\hline$\Delta R \mathrm{rs}, \mathrm{i} \%$ & $-18 \pm 11$ & $-28 \pm 15$ & 0.006 \\
\hline$\Delta R \mathrm{rs}, \mathrm{e} \%$ & $-10 \pm 15^{+}$ & $-23 \pm 16^{+}$ & 0.003 \\
\hline \multicolumn{4}{|c|}{ 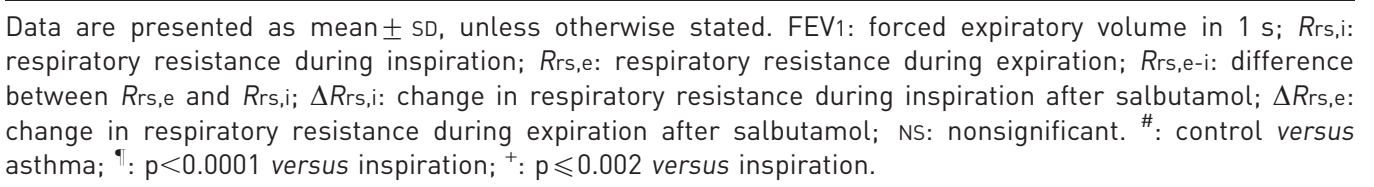 } \\
\hline
\end{tabular}

that measurements are performed during tidal breathing, the upper airway may significantly impact on the respiratory resistance $(R \mathrm{rs})$ [1,2]. The glottic aperture narrows during tidal expiration [3], contributing to Rrs being larger than in inspiration [2, 4, 5]. Acute bronchial obstruction promotes further laryngeal narrowing [6-8], which is expected to impact the Rrs measured during expiration. It is not known to what extent the mechanism is present in children with stable asthma, or whether the ability of Rrs to diagnose bronchial obstruction and reversibility is impeded in expiration. With a single excitation frequency, Rrs may

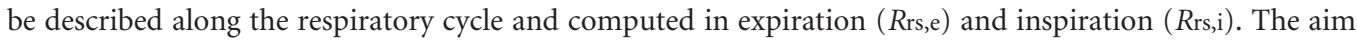
of this study was to compare Rrs,i and Rrs,e, their response to salbutamol and respective ability to separate asthmatics from controls. The hypothesis was that the diagnostic value of Rrs,e and its response to bronchodilator inhalation is impeded compared with Rrs,i.

Patients with asthma were diagnosed in the local paediatric pulmonology clinic (Hôpital d'enfants, CHU de Nancy, Nancy, France). All had discontinued their bronchodilator therapy $\geqslant 12 \mathrm{~h}$ prior to the study. Agematched healthy children served as controls. Written informed consent was obtained and the study was approved by the Ethics Committee (Comite de Protection des Personnes EST III, CHU de Nancy, Nancy, France). Pressure was oscillated at $8 \mathrm{~Hz}$ around the child's head to minimise upper airway wall motion (Pulmosfor; SEFAM, Villers-lès-Nancy, France). The measured signals were displayed and qualitycontrolled at the end of the acquisition, and Rrs,i and Rrs,e were averaged separately. Subsequently, forced spirometry was performed (Masterscope; Erich Jaeger GmbH, Wuertzburg, Germany). Measurements were repeated $10 \mathrm{~min}$ after inhalation of $200 \mu \mathrm{g}$ salbutamol (Ventoline; GlaxoSmithKline, Marly Le Roi, France). Data were compared using ANOVA and Fisher's t-test as needed. The ability of Rrs,i, Rrs,e and the percentage change in these values induced by salbutamol $(\Delta R \mathrm{rs}, \mathrm{i}$ and $\Delta R \mathrm{rs}, \mathrm{e})$ to separate asthmatics and controls was tested by calculating, at relevant thresholds, the Youden index, which is the simple sum of sensitivity and specificity minus one. It ranges from -1 for a nondiagnostic test to +1 for the ideal test. Maximal values (Ymax), corresponding sensitivity, specificity and threshold are reported.

55 asthmatics ( 36 males) and 23 controls (10 males) entered the study. 27 were taking inhaled steroids. Age, height and forced expiratory volume in $1 \mathrm{~s}$ (FEV1) z-score [9] were similar between groups (table 1). Asthmatics showed significantly larger Rrs,i and Rrs,e $(\mathrm{p} \leqslant 0.001)$ compared with controls. Rrs,e was larger than Rrs,i in both groups $(\mathrm{p}<0.001)$, but the difference between expiration and inspiration tended to be larger in asthmatics than controls $(\mathrm{p}=0.07)$ (table 1 ) and was negatively correlated with FEV1 z-score $(\mathrm{r}=-0.35, \mathrm{p}<0.01)$. Ymax was larger for Rrs,e than Rrs,i $(0.49$ versus 0.46 at respective thresholds of $8.6 \mathrm{hPa} \cdot \mathrm{s} \cdot \mathrm{L}^{-1}$ and $\left.7.0 \mathrm{hPa} \cdot \mathrm{s} \cdot \mathrm{L}^{-1}\right)$. The corresponding specificity was larger for $\operatorname{Rrs,e}(0.87)$ than $\operatorname{Rrs,i}(0.70)$, but sensitivity was lower $(0.62$ versus 0.76$)$. Asthmatic children presented a larger response to salbutamol than controls by both $R \mathrm{rs,i}$ and $R \mathrm{rs}$,e $(\mathrm{p}<0.007)$ (table 1$)$. While the response was larger in inspiration than expiration $(\mathrm{p}<0.0001), \Delta R \mathrm{rs}$,e showed a larger $Y \max$ than $\Delta R \mathrm{rs}, \mathrm{i}(0.49$ versus 0.37$)$ at respective thresholds of $-15 \%$ and $-19 \%$, with a corresponding better specificity $(0.75$ versus 0.65$)$ and sensitivity ( 0.74 versus 0.72$)$.

Altogether, the hypothesis that the ability of Rrs to identify asthma would be less in expiration than inspiration was not verified. Larger Rrs,e than Rrs,i at baseline are in keeping with prior reports from the 
literature $[2,4,5]$. Lung volume, a major determinant of airway resistance, would be unlikely to play a significant role, provided the time-triggered signal sampling did not bias the computation of tidal volume, due to asymmetry of breathing flow between inspiration and expiration. The fact that the difference between Rrs,e and Rrs,i, obtained with similar digitisation protocols, is not regularly found during artificial ventilation through an endotracheal tube in adults [10] or infants [11] gives indirect support to a role for the upper airways.

Glottis narrowing during expiration $[3,5]$ increases the upper airway resistance, particularly the nonlinear component [2]. Similar glottis responses in patients and controls would tend to blunt the difference related to the bronchoconstriction. In fact, a trend for a larger difference between expiration and inspiration was observed in asthma versus controls, a difference that related to the degree of airway obstruction. An interpretation of these findings could be that glottis adduction occurred in such a manner that the Rrs difference relative to control was reinforced during expiration. In other words, the laryngeal constriction would relate to the airway obstruction in children with stable asthma, as previously reported in adults during acute spontaneous or induced asthma [6-8].

Ymax was larger for Rrs,e than Rrs,i, suggesting the ability of FOT to separate controls from stable asthmatics was enhanced during expiration. Furthermore, the higher specificity of Rrs,e suggests a better identification of patients, i.e. fewer false positive responses, than that of Rrs,i. Threshold values disclosed for Rrs,e and Rrs,i with the current set-up may not be extrapolated to other FOT variants, since varying pressure around the head has been shown to provide larger Rrs than for standard input impedance. In addition, minimising the upper airway artefact was probably helpful in sharpening the Rrs difference between expiration and inspiration.

Compared with $\Delta R \mathrm{rs}, \mathrm{i}, \Delta R \mathrm{rs}$,e provided better discrimination between patients and controls, improving specificity and sensitivity, suggesting the reflex relaxation of laryngeal adductors associated with the bronchodilation potentiated the magnitude of the overall response in asthma. Different decision levels have been previously reported for $\Delta R \mathrm{rs}$ [12]. The current $15 \%$ decrease with $\operatorname{Rrs}$,e is somewhat lower than the $-30 \%$ Rrs cut-off reported by CALOGERo et al. [13], who used a standard input impedance device and estimated the threshold from the $95 \%$ confidence interval of healthy subjects in a large two-centre study, rather than from sensitivity-specificity analysis.

Finally, the potential of measuring Rrs,e by varying pressure around the head and its response to $200 \mu \mathrm{g}$ inhaled salbutamol in this cohort of children with stable asthma may not generalise to other conditions. In about half of the patients, inhaled steroids possibly had an indirect effect as a result of improving baseline obstruction, and a different picture might, thus, be observed in children with more severe bronchoconstriction or in response to a larger salbutamol dosage. In a completely different context, Rrs,i, rather than Rrs,e, was recommended in patients with chronic obstructive pulmonary disease, because expiratory flow limitation during tidal breathing is responsible for large Rrs swings [14] that result from the increase in airway impedance at the choke point [15].

We conclude that the ability of Rrs to separate asthmatic from healthy children is enhanced during expiration compared with inspiration, based on both measurement at baseline and assessment of response to bronchodilator. A likely mechanism relates to more pronounced expiratory glottis adduction in children with stable asthma compared with controls, reinforcing the group difference in Rrs,e at baseline and in response to salbutamol. The expiration-related measurement improves specificity and appears to ease the identification of patients while decreasing the rate of false negative responses.

0 @ERSpublications

Respiratory resistance assessment of bronchial obstruction: better asthma diagnosis in expiration than in inspiration http://ow.ly/uaMxS

Iulia Ioan $^{1}$, Laurianne Coutier ${ }^{2}$, Claude Bonabel ${ }^{1,2}$, Bruno Demoulin ${ }^{2}$, François Marchal ${ }^{1,2}$, Cyril Schweitzer ${ }^{1,2}$ and Silvia Varechova, ${ }^{1,2}$

${ }^{1}$ Service d'Explorations Fonctionnelles Pédiatriques, Hôpital d'Enfants, CHU de Nancy, Nancy, and ${ }^{2}$ EA 3450 DevAH Laboratoire de Physiologie, Faculté de Médecine, Université Lorraine, Vandoeuvre, France.

Correspondence: François Marchal, Service d'Explorations Fonctionnelles Pédiatriques, Hôpital d'Enfants, Rue du Morvan, 54511 Vandoeuvre, France. E-mail: f.marchal@chu-nancy.fr

Received: Oct 172013 | Accepted after revision: Feb 252014 | First published online: March 132014

Support statement: This work was supported by grant EA 3450 from Ministère de la Santé et de la Recherche Médicale.

Conflict of interest: None declared. 
Acknowledgements: The authors thank the children who participated and their families, and the primary school "Ecole de Brabois", Vandoeuvre, France.

\section{References}

1 Cauberghs M, Van de Woestijne KP. Mechanical properties of the upper airway. J Appl Physiol Respir Environ Exerc Physiol 1983; 55: 335-342.

2 Peslin R, Ying Y, Gallina C, et al. Within-breath variations of forced oscillation resistance in healthy subjects. Eur Respir J 1992; 5: 86-92.

3 Brancatisano T, Collett PW, Engel LA. Respiratory movements of the vocal cords. J Appl Physiol Respir Environ Exerc Physiol 1983; 54: 1269-1276.

4 Schweitzer C, Chone C, Marchal F. Influence of data filtering on reliability of respiratory impedance and derived parameters in children. Pediatr Pulmonol 2003; 36: 502-508.

5 Baier H, Wanner A, Zarzecki S, et al. Relationships among glottis opening, respiratory flow, and upper airway resistance in humans. J Appl Physiol Respir Environ Exerc Physiol 1977; 43: 603-611.

6 Collett PW, Brancatisano T, Engel LA. Changes in the glottic aperture during bronchial asthma. Am Rev Respir Dis 1983; 128: 719-723.

7 Higenbottam T. Narrowing of glottis opening in humans associated with experimentally induced bronchoconstriction. J Appl Physiol Respir Environ Exerc Physiol 1980; 49: 403-407.

$8 \quad$ Higenbottam T, Payne J. Glottis narrowing in lung disease. Am Rev Respir Dis 1982; 125: 746-750.

9 Stanojevic S, Wade A, Stocks J, et al. Reference ranges for spirometry across all ages: a new approach. Am J Respir Crit Care Med 2008; 177: 253-260.

10 Peslin R, Felicio da Silva J, Duvivier C, et al. Respiratory mechanics studied by forced oscillations during artificial ventilation. Eur Respir J 1993; 6: 772-784.

11 Gauthier R, Beyaert C, Feillet F, et al. Respiratory oscillation mechanics in infants with bronchiolitis during mechanical ventilation. Pediatr Pulmonol 1998; 25: 18-31.

12 Oostveen E, MacLeod D, Lorino $\mathrm{H}$, et al. The forced oscillation technique in clinical practice: methodology, recommendations and future developments. Eur Respir J 2003; 22: 1026-1041.

13 Calogero C, Simpson SJ, Lombardi E, et al. Respiratory impedance and bronchodilator responsiveness in healthy children aged 2-13 years. Pediatr Pulmonol 2013; 48: 707-715.

14 Gobbi A, Pellegrino R, Gulotta C, et al. Short-term variability in respiratory impedance and effect of deep breath in asthmatic and healthy subjects with airway smooth muscle activation and unloading. J Appl Physiol (1985) 2013; 115: 708-715.

15 Peslin R, Farré R, Rotger M, et al. Effect of expiratory flow limitation on respiratory mechanical impedance: a model study. J Appl Physiol (1985) 1996; 81: 2399-2406.

\section{Job strain and COPD exacerbations: an individual-participant meta-analysis}

To the Editor:

Chronic obstructive pulmonary disease (COPD) is a major cause of mortality and disability worldwide [1]. The clinical course of COPD is characterised by exacerbations, which can be minor and manageable at home or in primary care, or severe, leading to hospitalisation or even death. Known causes of exacerbations include tobacco smoke, air pollution, dusts and fumes, and respiratory infections $[1,2]$. One less well understood risk factor is stress, which could plausibly lead to COPD exacerbations as it can trigger inflammation [3,4] and is associated with increased smoking [5], which are both implicated in COPD pathology [2]. Work is an important source of stress in the age groups in which COPD is typically diagnosed $[1,6]$. However, we are not aware of previous investigations of work-related stress and the risk of COPD exacerbations.

In this study, we examined the associations between job strain (the most widely studied conceptualisation of work-related stress) and severe COPD exacerbations using individual-level data from 10 prospective cohort studies from the Individual Participant Data Meta-analysis in Working Populations (IPD-Work) Consortium [7]. Job strain is defined as a combination of high demands (excessive amounts of work) and low control (having little influence on what tasks to do and how to carry them out) at work.

We ascertained job strain from the participants' responses to questions on demands and control aspects of their work at study baseline. The responses were scored and for each participant, and mean scores were calculated for job-demand items and job-control items. Based on these, participants' job demands and job control were defined as high or low. A combination of high demands (a job demand score above the studyspecific median) and low control (job control score below the study-specific median) was defined as high 